\title{
Frequency Distribution of ABO/Rh Blood Group Systems in Breast Cancer, Yazd, 2007-2013
}

\author{
Seyyed Mostafa Shiryazdi ${ }^{1}$; Saeed $\operatorname{Kargar}^{1, *}$; Mohammad Ali Dehghan ${ }^{2}$; Hosein Neamatzadeh $^{3}$; \\ Mohaddeseh Aboueian-Jahromi ${ }^{3}$ \\ ${ }^{1}$ Department of General Surgery, Breast Diseases Research Center, Shahid Sadoughi University of Medical Sciences, Yazd, IR Iran \\ ${ }^{2}$ Shahid Sadoughi University of Medical Sciences, Yazd, IR Iran \\ 3 Breast Diseases Research Center, Shahid Sadoughi University of Medical Sciences, Yazd, IR Iran \\ *Corresponding author: Saeed Kargar, Department of General Surgery, Breast Diseases Research Center, Shahid Sadoughi University of Medical Sciences, Yazd. IR Iran. \\ E-mail: saeedkargar@yahoo.co m
}

Received: January 31, 2014; Accepted: March 5, 2014

\begin{abstract}
Background: The various studies related to different aspects of breast cancer has or is being carried out all over the world, but the breast cancer developing risk factors in patients and high-risk people have not been well understood yet. The $\mathrm{ABO} / \mathrm{Rh}$ systems blood group role as a factor increasing risk to getting some pathology has proven. So the survey of probable association between $\mathrm{ABO} / \mathrm{Rh}$ systems blood group and breast cancer can be useful.

Patients and Methods: This cross-sectional study included 197 women with breast cancer who referred to either Yazd Shahid Sadoughi hospital or Dr. Mortaz hospital during six years (2007 - 2013) because of diagnosis or treatment. The patient's demographic and clinical data were extracted and evaluated from their clinical documents.

Results: During 6 years, 375 reports of breast cancer were registered in 2 hospitals totally, that only data of 197 reports can be surveyed. The mean and limit of patient's age were $44 \pm 5.3$ years and $17-70$ years respectively. Most patients (93.4\%) have $\mathrm{Rh}^{+}$blood group system. Blood type $\mathrm{A}^{+}$was the most prevalent among patients. Then $\mathrm{O}^{+}$and $\mathrm{B}^{+}$was the most which their frequency distribution was $21.4 \%(42)$ and $9.1 \%$ (18) respectively. The least frequency distribution of this blood group system was related to $\mathrm{AB}^{+}$which is observed in only $4 \%$ (8) of patients. Conclusions: Blood type $\mathrm{A}^{+}$has the most association with breast cancer according to the findings this article and can be used as a paraclinical marker in treatment and consulting of patients and high-risk people.
\end{abstract}

Keywords: Breast Cancer; ABO Blood Group System; Rh Factor

\section{Background}

Breast cancer is the main reason of too early cancer related mortality in women [1]. After discovery of association between stomach cancer and blood type A by Arid and Bentall, various studies was carried out to find the relationship between $\mathrm{ABO}$ system blood group and disease [2]. From that time until now, various theories and studies in acceptance or rejection of chronic pathology association with blood group hypotheses has published [3, 4]. For example, some studies show an association between $A B O$ blood groups and pancreas, esophagus, cardia, surgically resected colon cancers or even Crimean-Congo hemorrhagic fever of children [5-11]. In contrast, some studies reject the association between $\mathrm{ABO}$ blood groups and skin cancer and radical cystectomy $[12,13]$. But in the recent studies especially by molecular genes techniques entrance like Genome-wide association survey technique, this subject is surveyed and evaluated in a different way [14]. Some factors like alcohol and family history are established risk factors of breast cancer $[15,16]$, but ABO blood group is not because of inconsistent results [17]. Usually older studies reject the association, but recent studies confirm the association between $\mathrm{ABO}$ blood groups and specific subtypes of breast cancer like ductal or familial. The association between $\mathrm{Rh}$ factor and breast cancer is also inconsistent [18]. Many studies had surveyed ABO/ $\mathrm{Rh}$ blood group system as a prognostic factor for breast cancer [2]. According to these studies there is a high incidence of blood type A among women developed breast cancer. Furthermore, it seems that the results of breast cancer treat in women with blood type A are not satisfactory and in this group of women the disease comeback possibility is more [18]. Meanwhile it is observed a kind of resistance to breast cancer in women with blood type $\mathrm{O}$ and if they develop this kind of cancer, their survival will be more than the other women with different blood groups. The cause of these findings is not definite, but it seems that genetic products of this genetic position allele can have antigenic role $[2,18]$.

Copyright (C) 2015, Zahedan University of Medical Sciences. This is an open-access article distributed under the terms of the Creative Commons Attribution-NonCommercial 4.0 International License (http://creativecommons.org/licenses/by-nc/4.0/) which permits copy and redistribute the material just in noncommercial usages, provided the original work is properly cited. 
ABO blood group system was described in 1900 by Landsteiner for the first time [19]. There are 3 alleles for ABO genetic position within human population and every human can inherit 2 alleles of this position with dominant or co-dominant pattern at the most [20]. Antigens of blood group has an important biologic role in the immunological system and effect on some tumors development like breast cancer [21].

To date, any studies have not yet published on $\mathrm{ABO}$ blood groups frequency distributions of breast cancer in Yazd. The aim of this study is to investigate $\mathrm{ABO} / \mathrm{Rh}$ blood group systems frequency distribution in breast cancer female patients admitted to Yazd hospitals in 2007 - 2013.

\section{Patients and Methods}

This cross-sectional study is carried out after Shahid Sadoughi University of Medical Sciences ethical committee confirmation by using registered data in clinical documents of female patients developed breast cancer that referred to either Yazd Shahid Sadoughi hospital or Dr. Mortaz hospital during 6 years (2007 - 2013) because of diagnosis or treatment.

The patients, whose blood groups were not registered in their records, are excluded from this study. Also, this matter was one of the limitations of this study. The sampling was non-probable and easy access. All of the clinical documents in both mentioned hospitals were surveyed.

To analyze collected data, first all of data is entered Excel Microsoft software, then analyzed by SPSS-17 statistical software. In this study, percentage, mean, and frequency distribution indices were used for describing descriptive data. Furthermore, $\chi^{2}$ and t-test statistical tests were defined in order to compare the results among the defined groups. P value results $\leq 0.05$ is considered significant.

\section{Results}

During 6 years 375 reports of breast cancer were registered in 2 hospitals totally that only data of 197 reports could be surveyed. The mean and limit of patient's age were $44 \pm 5.3$ and 17 - 70 years respectively. Frequency distribution of Rhesus system is given in Table 1 . Most patients to wit 184 (93.4\%) items have $\mathrm{Rh}^{+}$.

Most frequency distribution of ABO system blood group is relevant to blood type A which is observed in (129) 65.5\% patients (Table 2). Then, blood types $\mathrm{O}$ and $\mathrm{B}$ were the most which their frequency distributions were (42) 21.4\% and (18) $9.1 \%$ respectively. Finally, blood type AB has the least frequency distribution registered only in (8) $4 \%$. Statistical analyses show a significant relationship between $\mathrm{ABO}$ system blood groups frequency distribution and breast cancer incidence in patients $(\mathrm{P}=0.001)$.

$\mathrm{ABO}$ system blood group frequency distribution on the basis of Rh system is given in Table 3. Among patients with (A) blood group, more than $95 \%$ of people were $\mathrm{Rh}^{+}$. This finding is observed in 3 other blood groups of $\mathrm{ABO}$ system. Statistical analyses results show a significant relationship between $\mathrm{ABO} / \mathrm{Rh}^{+}$system blood groups frequency distribution and breast cancer among patients $(\mathrm{P}=0.024)$.

Table 1. Frequency Distribution of Patients on the Basis of ABO System Blood Group ${ }^{\text {a }}$

\begin{tabular}{lcc}
\hline Blood Groups & Frequency Distribution of Patients & Frequency Distribution of Yazd People \\
\hline $\mathbf{R h}{ }^{+}$ & $184(93.4)$ & $36657(87)$ \\
$\mathbf{R h}$ & $13(6.6)$ & $6469(14)$ \\
Total & $197(100)$ & $43126(100)$ \\
\hline
\end{tabular}

a Data are presented as No. (\%).

Table 2. Frequency Distribution of Patients on the Basis of ABO System Blood Group ${ }^{\text {a }}$

\begin{tabular}{lcc}
\hline Blood Groups & Frequency Distribution of Patients & Frequency Distribution of Yazd People \\
\hline A & $129(65.5)$ & $11213(26)$ \\
B & $18(9.1)$ & $13369(31)$ \\
AB & $8(4)$ & $3881(9)$ \\
O & $42(21.4)$ & $14663(34)$ \\
Total & $197(100)$ & $43126(100)$ \\
\hline
\end{tabular}

a Data are Presented as No. (\%). 
Table 3. ABO System Blood Group Frequency Distribution on the Basis of Rhesus System Among Patients a

\begin{tabular}{|c|c|c|}
\hline ABO & Frequency Distribution of Patients & Frequency Distribution of Yazd People \\
\hline \multicolumn{3}{|l|}{ A } \\
\hline $\mathrm{Rh}^{+}$ & $123(95.3)$ & $9888(22)$ \\
\hline $\mathrm{Rh}^{-}$ & $6(4.7)$ & $1725(4)$ \\
\hline Total & 129 & $11613(26)$ \\
\hline \multicolumn{3}{|l|}{ B } \\
\hline $\mathrm{Rh}^{+}$ & $16(8.9)$ & $11644(27)$ \\
\hline $\mathrm{Rh}^{-}$ & $2(1.1)$ & $1725(4)$ \\
\hline Total & 18 & $13369(31)$ \\
\hline \multicolumn{3}{|l|}{$\mathbf{A B}$} \\
\hline $\mathrm{Rh}^{+}$ & $6(75)$ & $3850(8)$ \\
\hline $\mathrm{Rh}^{-}$ & $2(25)$ & $431(1)$ \\
\hline Total & 8 & $4281(9)$ \\
\hline \multicolumn{3}{|l|}{ O } \\
\hline $\mathrm{Rh}^{+}$ & $39(92.8)$ & $12507(29)$ \\
\hline $\mathrm{Rh}^{-}$ & $3(7.2)$ & $2156(5)$ \\
\hline Total & 42 & $14663(34)$ \\
\hline
\end{tabular}

\section{Discussion}

According to our results, blood type A has the most frequency distribution among women with breast cancer. Breast cancer is the second cause of death due to cancer among women. It is estimated that more than 1.5 new items of breast cancer occur in the world, annually [14]. Because of highly complex nature of this cancer, it is probable relationship with various factors is surveyed [2]. Because of finding a kind of association between $A B O$ system blood group and some malignancies like stomach cancer, various studies try to find an association between this system blood group and breast cancer which the results of some are considerable and valuable [2, 4, 14, $18,20,22]$. This study, also tries to survey this association by using data extracted from medical records of patients developed breast cancer.

Thoroughly, frequency distribution numbers of women developed breast cancer with $\mathrm{Rh}^{-}$were less than numbers patients with $\mathrm{Rh}^{+}$. The frequency distribution numbers of Rh in Yazd people community are similar to those of women with breast cancer. This finding can be observed in many previous studies with similar objectives or even in other studies control or analyze Rh frequency distribution relating to different subjects. Basically, the frequency of women with $\mathrm{Rh}^{-}$is much less compared to men with $\mathrm{Rh}$ - In fact, this matter is an evolutionary event. Because during the first delivery, there is a possible that some newborn's blood with $\mathrm{Rh}^{+}$enters in mother's blood with $\mathrm{Rh}^{-}$and antibodies against it is produced during the second pregnancy, the newborn with $\mathrm{Rh}^{-}$will be aborted or gotten mental retardation [22,23]. So in our study, there is not any association between $\mathrm{Rh}$ factor and breast cancer. Also Miao et al. [17] in a meta-analysis study conclude that $\mathrm{Rh}$ factor is not associated with breast cancer. Yu et al. [24] show there is not any difference between $\mathrm{Rh}^{+}$and $\mathrm{Rh}^{-}$in breast cancer specific mortality. But Stamatakos et al. [21] in a study show relative risk of metastasis in patients with $\mathrm{Rh}^{-}$is more than patients with $\mathrm{Rh}^{+}$by 4.2 times. Ronco et al. [25] conclude $\mathrm{Rh}^{-}$is associated with risk of breast cancer and positive history of first degree relatives.

According to this article finding, the prevalence of breast cancer is observed in women with blood type A. Then, the frequency distribution of patients with $\mathrm{O}^{+}$and $\mathrm{B}^{+}$blood type was the most. Association between $\mathrm{ABO}$ blood group system and breast cancer has not yet accepted generally, because of little data or probably because of lack knowledge about this finding application in breast cancer treatment or management [17]. Recently, antigen A is associated with high risk of developing aggressive ductal cancer in 166 women [26]. Also Miao et al. by surveying 14 studies state Caucasians with blood type A may have higher risk of breast cancer than other Caucasians, but there is not any association in other groups [17].

Stamatakos et al. [21] show that comparing to other blood groups and specially blood type $\mathrm{AB}$ (3.6\%), blood type A (49.6\%) often associates with ductal breast cancer. They state blood type A has the worst prognostic. Akhtar et al. [27] conclude blood group A increases significantly in breast cancer (42.4\%). Cihan [28] shows that overall 
and disease-free survival times are more in blood groups A and B than the other groups. Tryggvadottir et al. [17] deduce blood group $\mathrm{B}$ prevalence in hereditary breast cancer is 2-folds more than sporadic. Gates et al. [18] in a research, conclude there is not any association between $\mathrm{ABO}$ blood group and breast cancer risk or survival. Sharma et al. [2], Flavarjani et al. [30] with 549 Isfahani women sample, Dede et al. [31] and Costantini et al.[32] show ABO blood group is not a risk factor for breast cancer. Also, Yu et al. [24] conclude $\mathrm{ABO} / \mathrm{Rh}$ blood group is not associated with triple-negative breast cancer.

The least number of breast cancer items is observed in women with $\mathrm{AB}^{+}$blood type. This finding is confirmed repeatedly by previous studies. For instance, in a study carried out by Guleria et al. [23] with a statistical sample size of 42 people, it has been reported that only 7 (16.6\%) of the total items have blood type AB. Holdsworth et al. [22] also conducted a study among 1001 patients develop breast cancer, report that the least frequency distribution of $A B O$ system blood group is relevant to blood type $\mathrm{AB}$ (only 31 items). The recent study is the first study into the survey of association between blood groups and breast cancer. In this study, introduce $\mathrm{ABO}$ blood group system as a prognostic indicator of breast cancer. Mehdi et al. [14] had conducted a study among 200 women developed breast cancer in Al-Nassyria city of Iraq, report the least frequency distribution of breast cancer is relevant to women with blood type $A B$ (10\% of items). Stamatakos et al. show in patients with $\mathrm{AB}$ blood group, ductal type of breast cancer occurs rarely [21]. Furthermore this finding is also reported in some other studies consist of Iodice et al. [33]. It seems that there is a common consent among previous studies that the risk of breast cancer incidence in blood type $A B$ is less than other blood groups of ABO system [3,34].

The reasons of different assessment risk between $\mathrm{ABO}$ blood groups and breast cancer are different frequency ABO blood group between two populations, importance of case and comparative control and determining way of ABO blood groups [27]. Selection of appropriate control group is very important for these groups because of different distribution $\mathrm{ABO}$ blood groups in various ethnic groups [8].

According to the finding of this study, it seems that there is an association between $\mathrm{ABO} / \mathrm{Rh}$ blood groups and breast cancer and the possibility of breast cancer in women with blood type $\mathrm{A}^{+}$is more than other blood groups of $\mathrm{ABO}$ system. Therefore, it is recommended the $\mathrm{ABO} / \mathrm{Rh}$ system blood groups control should be considered as a possible risk-factor for breast cancer. Anyway, conducting other studies with greater statistical sample size is essential.

\section{Acknowledgements}

The authors thank to blood transfusion service of Yazd and medical records units of mentioned hospitals. This article is resulted from a medical student thesis of Shahid
Sadoughi University of Medical Sciences, Yazd. The thesis was completed by Mohammad Ali Dehghan as a medical student and Dr. Seyyed Mostafa Shiryazdi as an advisor.

\section{Authors' Contributions}

Seyyed Mostafa Shiryazdi and Mohammad Ali Dehghan participated in the design of the study and manuscript. Mohammad Ali Dehghan carried out the study. Saeed Kargar, Hosein Neamatzadeh, and Mohaddeseh AboueianJahromi helped to design and draft the manuscript. All authors read and approved the final manuscript.

\section{Funding/Support}

The funding related to this study was performed by Shahid Sadoughi University of Medical Sciences, Yazd, IR Iran.

\section{References}

1. Madeira KP, Daltoe RD, Sirtoli GM, Carvalho AA, Rangel LB, Silva IV. Estrogen receptor alpha (ERS1) SNPs c454-397T >C (PvuII) and c454-351A $>$ G (XbaI) are risk biomarkers for breast cancer development. Mol Biol Rep. 2014;41(8):5459-66.

2. Sharma G, Choudhary R, Bharti D. Studies showing the relationship between $\mathrm{ABO}$ blood groups and major types of cancers. Asian J Exp Sci. 2007;20(1):129-32.

3. Aird I, Bentall HH, Roberts JA. A relationship between cancer of stomach and the ABO blood groups. Br Med J. 1953;1(4814):799801.

4. Sant M, Allemani C, Santaquilani M, Knijn A, Marchesi F, Capocaccia R, et al. EUROCARE-4. Survival of cancer patients diagnosed in 1995-1999. Results and commentary. Eur J Cancer. 2009;45(6):93191.

5. Wolpin BM, Chan AT, Hartge P, Chanock SJ, Kraft P, Hunter DJ, et al. ABO blood group and the risk of pancreatic cancer. J Natl Cancer Inst. 2009;101(6):424-31.

6. Ben Q, Wang K, Yuan Y, Li Z. Pancreatic cancer incidence and outcome in relation to $\mathrm{ABO}$ blood groups among Han Chinese patients: a case-control study. Int J Cancer. 2011;128(5):1179-86.

7. Wolpin BM, Kraft P, Gross M, Helzlsouer K, Bueno-de-Mesquita HB, Steplowski E, et al. Pancreatic cancer risk and ABO blood group alleles: results from the pancreatic cancer cohort consortium. Cancer Res. 2010;70(3):1015-23.

8. Su M, Lu SM, Tian DP, Zhao H, Li XY, Li DR, et al. Relationship between $\mathrm{ABO}$ blood groups and carcinoma of esophagus and cardia in Chaoshan inhabitants of China. World J Gastroenterol. 2001;7(5):657-61.

9. Cao X, Wen ZS, Sun YJ, Li Y, Zhang L, Han YJ. Prognostic value of ABO blood group in patients with surgically resected colon cancer. British J Cancer. 2014;111(1):174-80.

10. Guven AS, Sancakdar E, Kaya A, Uysal EB, Oflaz MB, Bolat F, et al. Value of $A B O$ blood group in predicting the severity of children with Crimean-Congo hemorrhagic fever. Int J Clin Exp Med. $2014 ; 7(2): 416-20$

11. Kumar N, Kapoor A, Kalwar A, Narayan S, Singhal MK, Kumar A, et al. Allele frequency of $\mathrm{ABO}$ blood group antigen and the risk of esophageal cancer. Biomed Res Int. 2014;2014:286810.

12. Tursen U, Tiftik EN, Unal S, Gunduz O, Kaya TI, Camdeviren H, et al. Relationship between $\mathrm{ABO}$ blood groups and skin cancers. Dermatol Online J. 2005;11(3):44.

13. Suer E, Ozcan C, Gokce I, Gulpinar O, Gogus C, Turkolmez K, et al. Do blood groups have effect on prognosis of patients undergoing radical cystectomy? Int Urol Nephrol. 2014;46(8):1521-6.

14. Mehdi LM, Saleh HS, Al-Fartosi KG. Relationship between ABO blood group and breast cancer at AL-Nassyria city/Iraq. J Thi Qar Sci. 2008;1(1):1-5.

15. Park SY, Kolonel LN, Lim U, White KK, Henderson BE, Wilkens LR. Alcohol consumption and breast cancer risk among women 
from five ethnic groups with light to moderate intakes: the Multiethnic Cohort Study. Int J Cancer. 2014;134(6):1504-10.

16. Key TJ, Verkasalo PK, Banks E. Epidemiology of breast cancer. Lancet Oncol. 2001;2(3):133-40.

17. Miao SY, Zhou W, Chen L, Wang S, Liu XA. Influence of ABO blood group and Rhesus factor on breast cancer risk: a meta-analysis of 9665 breast cancer patients and 244,768 controls. Asia Pac J Clin Oncol. 2014;10(2):101-8.

18. Gates MA, Xu M, Chen WY, Kraft P, Hankinson SE, Wolpin BM. ABO blood group and breast cancer incidence and survival. Int J Cancer. 2012;130(9):2129-37.

19. Daniels G. The molecular genetics of blood group polymorphism. Transpl Immunol. 2005;14(3-4):143-53.

20. Anderson DE, Haas C. Blood type A and familial breast cancer. Cancer. 1984;54(9):1845-9.

21. Stamatakos M, Kontzoglou K, Safioleas P, Safioleas C, Manti C, Safioleas M. Breast cancer incidence in Greek women in relation to ABO blood groups and Rh factor. Int Semin Surg Oncol. 2009;6:14.

22. Holdsworth PJ, Thorogood J, Benson EA, Clayden AD. Blood group as a prognostic indicator in breast cancer. Bmj. 1985;290(6469):671-3.

23. Guleria K, Singh HP, Kaur H. ABO blood groups in gastrointestinal tract (GIT) and breast carcinoma patients. Anthropologist. 2005;7(3):189-92.

24. Yu J, Gao F, Klimberg VS, Margenthaler JA. ABO blood type/Rh factor and the incidence and outcomes for patients with triplenegative breast cancer. Ann Surg Oncol. 2012;19(10):3159-64 .

25. Ronco AL, Stoll M, De Stefani E, Maisonneuve JE, Mendoza BA, Deneo-Pellegrini H. Rh factor, family history and risk of breast cancer: a case-control study in Uruguay. Cancer Detect Prev.

\section{9;32(4):277-85.}

26. Rummel S, Shriver CD, Ellsworth RE. Relationships between the ABO blood group SNP rs505922 and breast cancer phenotypes: a genotype-phenotype correlation study. BMC Med Genet. 2012;13:41.

27. Akhtar K, Mehdi G, Sherwani R, Sofi L. Relationship between various cancers and ABO blood groups: A northern India experience. Int J Pathol. 2010;13(1):3-7.

28. Cihan YB. Significance of ABO-Rh blood groups in response and prognosis in breast cancer patients treated with radiotherapy and chemotherapy. Asian Pac J Cancer Prev. 2014;15(9):4055-60.

29. Tryggvadottir L, Tulinius H, Robertson JM. Familial and sporadic breast cancer cases in Iceland: a comparison related to $\mathrm{ABO}$ blood groups and risk of bilateral breast cancer. Int J Cancer. 1988;42(4):499-501.

30. Flavarjani AH, Hedayatpour B, Bashardoost N, Nourian SM. Study of the association between blood types and breast cancer among Isfahanian women with breast cancer. Adv Biomed Res. 2014;3:43.

31. Dede DS, Aksoy S, Dizdar O, Cerci P, Gullu I, Ozisik Y, et al. Blood ABO groups and risk of breast cancer. Med Oncol. 2010;27(4):1433.

32. Costantini M, Fassio T, Canobbio L, Landucci M, Resasco M, Boccardo F. Role of blood groups as prognostic factors in primary breast cancer. Oncology. 1990;47(4):308-12.

33. Iodice S, Maisonneuve P, Botteri E, Sandri MT, Lowenfels AB. ABO blood group and cancer. EurJ Cancer. 2010;46(18):3345-50.

34. Nakagoe T, Nanashima A, Sawai T, Tuji T, Ohbatake M, Jibiki M, et al. Expression of blood group antigens A, B and $\mathrm{H}$ in carcinoma tissue correlates with a poor prognosis for colorectal cancer patients.J Cancer Res Clin Oncol. 2000;126(7):375-82. 